\title{
Design, fabrication and characterization of a novel gas microvalve using micro- and fine-machining
}

\author{
I Fazal, M C Louwerse, H V Jansen and M C Elwenspoek \\ MESA+ Research Institute, University of Twente EWI/TST, PO Box 217 Enshede, \\ The Netherlands \\ E-mail: I.Fazal@ewil.utwente.nl
}

Received 20 March 2006, in final form 4 April 2006

Published 5 May 2006

Online at stacks.iop.org/JMM/16/1207

\begin{abstract}
In this paper, we present the design, fabrication and characterization of a novel gas microvalve realized by combining micro- and fine-machining techniques. The design is for high flow rates at high pressure difference between inlet and outlet, burst pressure of up to 15 bars. There is no power consumption required for the valve to maintain its position during operation in any intermediate state and the process gas does not interact with the actuation mechanism. The microvalve was experimentally characterized with air flows. It is shown that flow rates of $220 \mathrm{ml} \mathrm{min}^{-1}$ at a pressure difference of 4 bars could be achieved with a minimum accurate flow rate of $4 \mathrm{ml} \mathrm{min}^{-1}$.
\end{abstract}

(Some figures in this article are in colour only in the electronic version)

\section{Introduction}

A fundamental component of any microfluidic systems is the microvalve [1]. In recent years, a great deal of research has been conducted to design and develop microvalves for different fluidic systems. These systems involve the integration of many individual steps performed in chemical analysis. This requires the ability to control the large flow precisely and efficient transport of reagents and samples throughout different parts of the system with lowest amount of gas leakage. Therefore, valves must be designed in such a way that it is capable of controlling the large flow precisely, consuming less power and exhibit the characteristic of leak tightness. Here, a successful attempt has been made to design a high-pressure valve which can control large flow rates precisely at any intermediate state with no power consumption. Additionally, care has been taken that the process gas does not interact with the actuation mechanism.

Many efforts have been made to develop various microvalves to meet different requirements for specific applications [2-9]. Though the configurations of these valves could be different (open or closed valve), the structures are very similar. Generally, they have a deflectable membrane and a valve seat with inlet and outlet. When the membrane is deflected, it seals the inlet on the valve seat and closes the valve. When comparing these micro-machined gas valves with the conventional valves, one finds poor flow capacity, high power consumption, slow response and low operating pressure in micro-machined valves. There are different reasons for this such as small cross-sectional area in micro-machined fluid geometries (channels and orifices), limits the flow and occurrence of high forces during control of gas, pressurized at elevated pressure, demand high actuator performance such as high force with less power consumption. Different actuators can deliver certain amount of force or work depends upon their geometries. Therefore, the actuator's stroke and the forces delivered are limited. Table 1 gives an overview of earlier demonstrated microvalve [3-9]. Some of these valves meet most of the requirements, such as high inlet pressure, low leakage and process gas isolation but have relatively low flow rates [2, 3, 6, 7]. In addition, these valves have relatively high power consumption and no control of flow at intermediate states between open and closed positions. These valves use different actuation mechanisms such as thermal, pneumatic, thermopneumatic, electromagnetic, piezoelectric, etc. The valves with thermal [4-7] and thermopneumatic [8] actuation provide large force through large stroke but show slow response time (>300 ms) and high leakage. Thermally 
Table 1. Overview of gas microvalves.

\begin{tabular}{|c|c|c|c|c|c|c|c|c|c|c|}
\hline \multirow[b]{2}{*}{ Type } & \multicolumn{5}{|c|}{ Performance } & \multicolumn{3}{|c|}{ Configuration } & \multirow[b]{2}{*}{ Comments } & \multirow[b]{2}{*}{ References } \\
\hline & $\begin{array}{l}Q \\
(\mathrm{ml} \mathrm{min} \\
\left.\min ^{-1}\right)\end{array}$ & $\begin{array}{l}\Delta P \\
\text { (bar) }\end{array}$ & $\begin{array}{l}\text { Power } \\
(\mathrm{mw})\end{array}$ & $\begin{array}{l}\text { Leak } \\
\left(\mathrm{ml} \mathrm{min}^{-1}\right)\end{array}$ & Size $\left(\mathrm{mm}^{3}\right)$ & $\begin{array}{l}\text { Response } \\
\text { time }(\mathrm{ms})\end{array}$ & $\begin{array}{l}\text { Open/ } \\
\text { closed }\end{array}$ & $\begin{array}{l}\text { Intermediate } \\
\text { position }\end{array}$ & & \\
\hline Piezoelectric & 52 & 20 & 180 & $5 \times 10^{-3}$ & $5 \times 6 \times 8.4$ & $30 \mu \mathrm{s}$ & Yes & No & Boss type & [2] \\
\hline Pneumatic & 120 & 25 & - & - & $\approx 5 \times 5 \times 2$ & 400 & Yes & No & $\begin{array}{l}\text { Pressure } \\
\text { balance }\end{array}$ & [3] \\
\hline Bimetallic & 800 & 6 & 1000 & 80 & $6 \times 6 \times 2$ & $<300$ & Yes & No & three-way & {$[4]$} \\
\hline Bimetallic & 500 & 0.5 & 300 & 0.3 & $7.3 \times 5.8 \times 1.2$ & $<300$ & Yes & No & Membrane & [5] \\
\hline Bimetallic & 150 & 3.4 & & 0.3 & - & 300 & Yes & No & Membrane & [6] \\
\hline Thermal & 100 & 25 & 500 & - & $17 \times 6 \times 23^{\mathrm{a}}$ & 100 & Yes & No & Membrane & [7] \\
\hline Thermopneumatic & 400 & 2 & 350 & $10^{-3}$ & - & $<200$ & Yes & No & Membrane & [8] \\
\hline Electromagnetic & 3 & 16 & 6000 & - & $\approx 12 \times 15 \times 2$ & 0.4 & Yes & No & Membrane & [9] \\
\hline This work & 220 & 4 & $300^{\mathrm{b}}$ & $5 \times 10^{-6}$ & $15 \times 15 \times 30^{\mathrm{a}}$ & 30 & Yes & Yes & Membrane & \\
\hline
\end{tabular}

${ }^{a}$ Valve size with packaging.

${ }^{\mathrm{b}}$ Power consumption only for one step, not continuous.

actuated valves also suffer from the risk of random valve opening if ambient cooling or heating occurs. It results in an uncontrolled initiation of the actuation mechanism. On the other hand, electromagnetic valves [9, 10] offer large force but high heat dissipation and large power consumption. Most of the valves presented above do not exhibit the property to precisely control the high flow rates at considerably high inlet-outlet pressure difference. Additionally, the existing valves are not capable of controlling the flow without power consumption at different intermediate states during valve operation.

In this paper, we describe the design, fabrication and characterization results for a high flow rate, leak tight microvalve, operating under high inlet pressures. We present a new approach, based on the combination of fine- and micromachining. The valve is composed of two main parts. The first is the fine-machined actuation part. It includes a stepper motor (an electromagnetic actuator) along with metal screw to convert rotary motion into translational motion. The second part is the microvalve, realized by standard micro-machined techniques. This new design provides the following benign features:

- An electromagnetic mini-motor is used for the actuation.

- The mechanical transmission technique (stepper motor along with screw) allows coping with a pressure range of $1-9.0$ bars for controlling the flow rates of 20 $1500 \mathrm{ml} \mathrm{min}^{-1}$.

- It offers the control of flow at any intermediate state from open to closed position.

- It is not open or closed valve in the sense that there is no power required to keep the valve open in any desired state.

- The process gas is isolated from the actuation part.

- This specific configuration of microvalve is leak tight.

- The response time is $<30 \mathrm{~ms}$.

The size of the reported microvalve is limited by the actuator as it is the biggest component of the microvalve. However, the complete device can be realized within the size limit of few cubic centimeters.

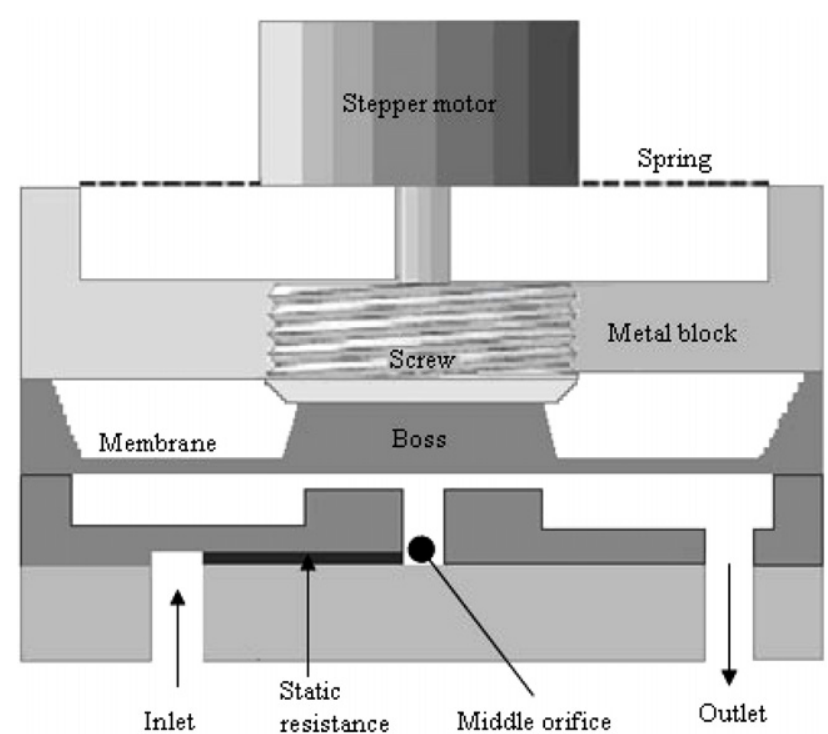

Figure 1. Schematic cross-sectional view of the microvalve.

\section{Valve design and modeling}

The significant factors in designing microvalve are as follows:

- Valve design should be compatible with high inlet pressure to deliver high flow rates.

- The valve should be designed in such a way that the flow should not be in the regime of high Mach numbers as it affects the performance of the valve.

- Selection of adequate actuation, which is well matched to the force needed to control the valve operation.

All the aforementioned factors have been considered before designing the valve. The schematic cross-sectional view of the valve is shown in figure 1 . The core components of the microvalve are divided into two parts: fine-machined and micro-machined, respectively. The first part, which is fine-machined, comprises a metal block along with a screw, which is rotated by the micro stepper motor mounted on a spring. The screw mechanism is used to convert the rotary 


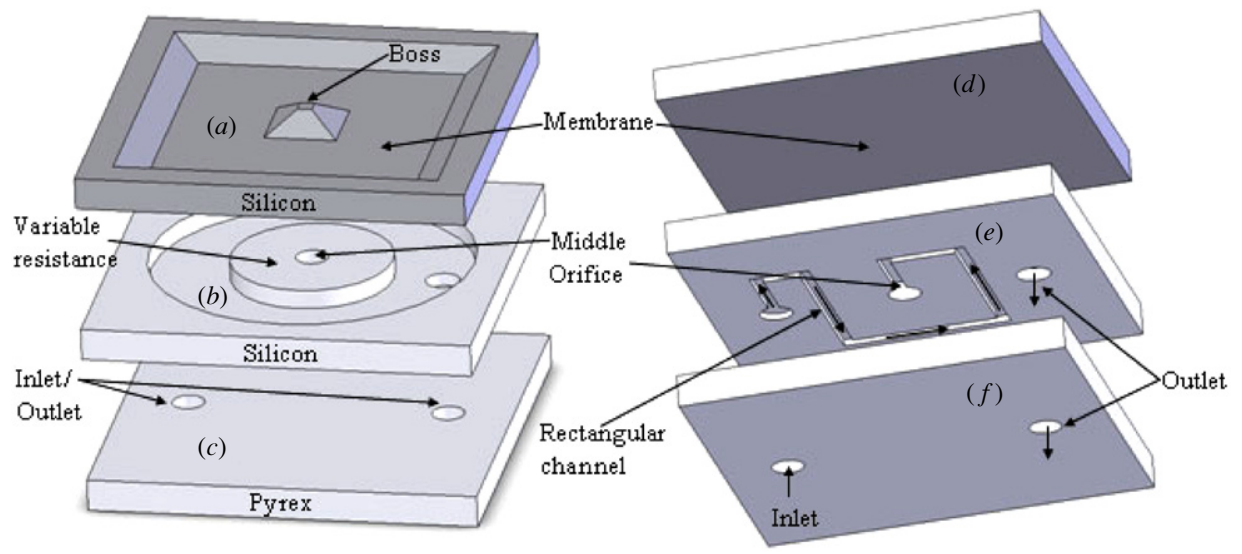

Figure 2. Micro-machined valve.

motion of the stepper motor into translational motion in order to deflect the silicon membrane. The combination of stepper with screw provides the benevolent feature of controlling the flow at any intermediate state without continuous power consumption. Upon actuation, stepper motor rotates the metal screw which deflects the membrane to control the flow. Screw position remains unchanged due to the friction between the threads, which keeps the membrane in deflected state even when stepper motor is switched off. This mechanism keeps the valve in operation at any state without the need of continuous power supply.

The second part is the micro-machined valve made from three wafers (see figure 2). The Pyrex wafer has the inlet and the outlet orifices (see figure 2(c)). The middle wafer is from silicon which carries the valve seat that acts as a variable resistance, and also contains a rectangular channel at its bottom, which acts as a static resistance. The inlet in the Pyrex wafer opens in this rectangular channel which is connected to the valve seat by the middle orifice (see figures $2(b)$ and $(e)$ ). The top wafer is also from silicon having a square membrane with a boss, which controls the gas flow upon deflection (see figure 2(a)).

In the following section, modeling of the micro- and finemachined parts is explained in detail.

\subsection{Micro-machined part}

To derive specifications of the microvalve that can withstand high pressure and can precisely control high flow rates, a new approach of integrating two resistances in series is adopted. The two resistances, in which one is variable and the other is static resistance, are designed to achieve linearity over a wide range. For the variable resistance, a theoretical model for circumferential gas flow is introduced [11, 12]. Figure 3 shows the typical design for a circumferential gas flow when using silicon micro-machining techniques. In this design, flow is controlled by the gap height $s$. By changing the gap height, the resistance is changed.

Assuming laminar, incompressible and fully developed flow, the variable resistance is calculated by $[11,12]$

$$
R=\frac{6 \mu \ln \left(\frac{a_{2}}{a_{1}}\right)}{s^{3} \pi},
$$

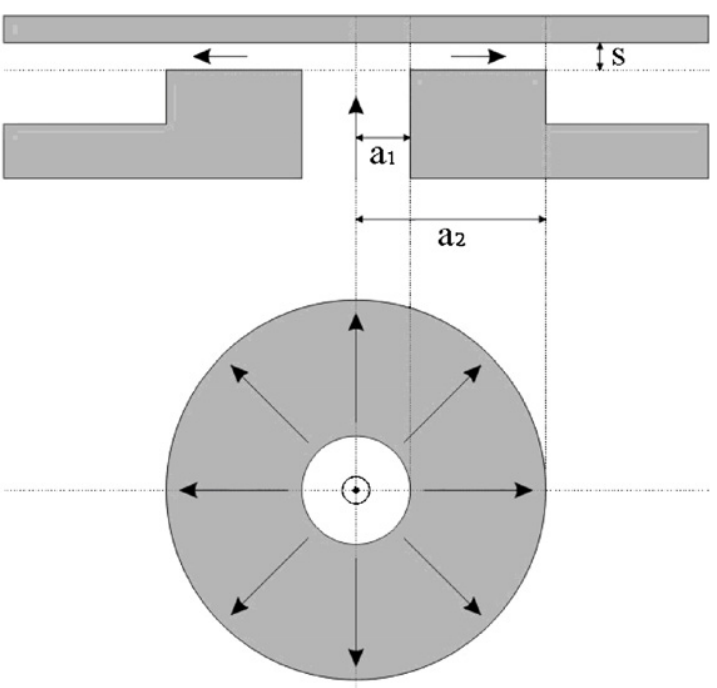

Figure 3. Circumferential flow.

where $\mu$ is the fluid viscosity, $a_{1}$ and $a_{2}$ are the inner and the outer radii of the valve seat, respectively, as shown in figure 3 . Similarly, for the static resistance, the gas flow is modeled in a rectangular cross section and is given by

$$
R=\frac{12 l}{w h^{3}} \mu,
$$

where $l$ is the length of the channel and $w$ and $h$ are the width and the height of the channel, respectively.

The flow rate can then be written as

$$
\varphi=\frac{\Delta P s^{3} h^{3} w \pi}{6 w h^{3} \mu \ln \left(\frac{a_{2}}{a_{1}}\right)+12 l s^{3} \mu \pi} .
$$

The valve is designed for a maximum flow of $220 \mathrm{ml} \mathrm{min}^{-1}$ at inlet/outlet pressure difference of 4 bars. Typical dimensions of 0.2 and $2 \mathrm{~mm}$ are chosen for $a_{1}$ and $a_{2}$, respectively, to achieve the flow rate of $220 \mathrm{ml} \mathrm{min}{ }^{-1}$. Similarly, dimensions of $400 \mu \mathrm{m}, 60 \mu \mathrm{m}$ and $32 \mathrm{~mm}$ are chosen for $w, h$ and $l$, respectively, for the rectangular channel. Figure 4 shows the flow rate as a function of gap height $s$ for the variable resistance only and for both resistances in series. It can be seen from the graph that only in the case of variable resistance, the flow rate rises steeply, which makes control difficult. But from the 


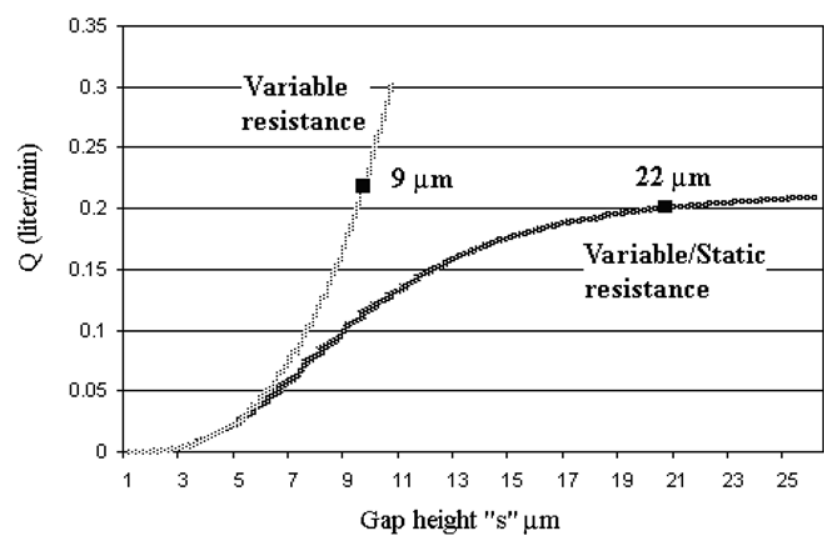

Figure 4. Flow rate as a function of gap height $s$.

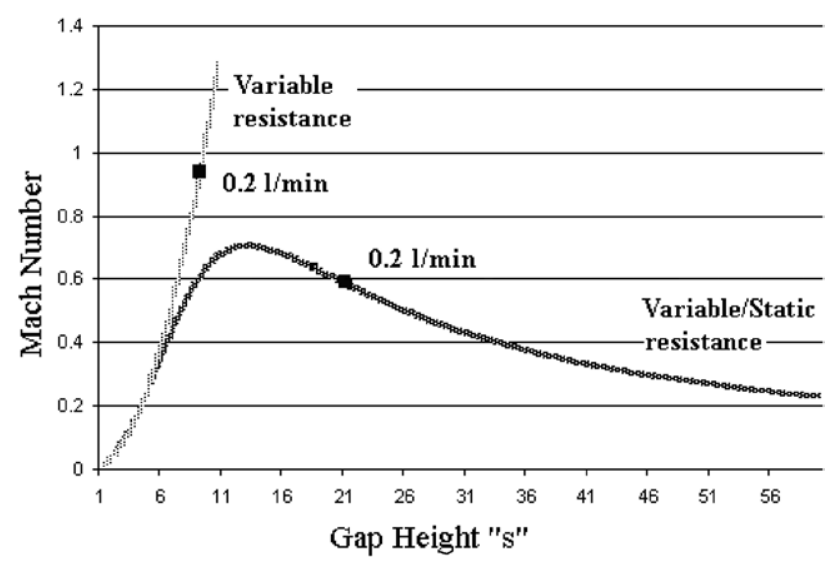

Figure 5. Mach number as a function of gap height $s$.

second curve, it can be observed that the introduction of static resistance in series with the variable resistance provides more linearity. In fact, the static resistance controls the flow for the large opening of the variable resistance, while for smaller opening the variable resistance controls the flow. It can also be seen that the combination of these resistances provides a larger range of deflecting the membrane for controlling the gas flow. The membrane can deflect $22 \mu \mathrm{m}$ instead of $9 \mu \mathrm{m}$, which is important for the better controllability. Additionally, the steepest part of the curve shown in figure 4 which determines the smallest step needed to control the flow of $4 \mathrm{ml} \mathrm{min}^{-1}$ is $200 \mathrm{~nm}$. It means that the membrane has to deflect minimum $200 \mathrm{~nm}$ per step to get the required flow.

The performance of the valve is also measured in terms of fluctuation in the flow velocity. And these velocities can be represented by a dimensionless number known as the Mach number. The Mach number in variable and static resistances can be defined as

$$
\begin{aligned}
& M a_{\mathrm{v}}=\frac{V_{\mathrm{v}}}{c_{\mathrm{air}}}=\frac{\varphi}{c_{\mathrm{air}} A_{\mathrm{s}}}=\frac{\varphi}{2 \pi a_{1} s} \\
& M a_{\mathrm{s}}=\frac{V_{\mathrm{v}}}{c_{\mathrm{air}}}=\frac{\varphi}{c_{\mathrm{air}} A_{\mathrm{s}}}=\frac{\varphi}{c_{\mathrm{air}} w h},
\end{aligned}
$$

where $c_{\text {air }}$ is the speed of sound in air, $V_{\mathrm{v}}$ and $V_{\mathrm{s}}$ are the mean velocities and $A_{\mathrm{v}}$ and $A_{\mathrm{s}}$ are the smallest areas in the variable and static resistances, respectively. A plot of the Mach number against gap height $s$ is shown in figure 5. It can be seen

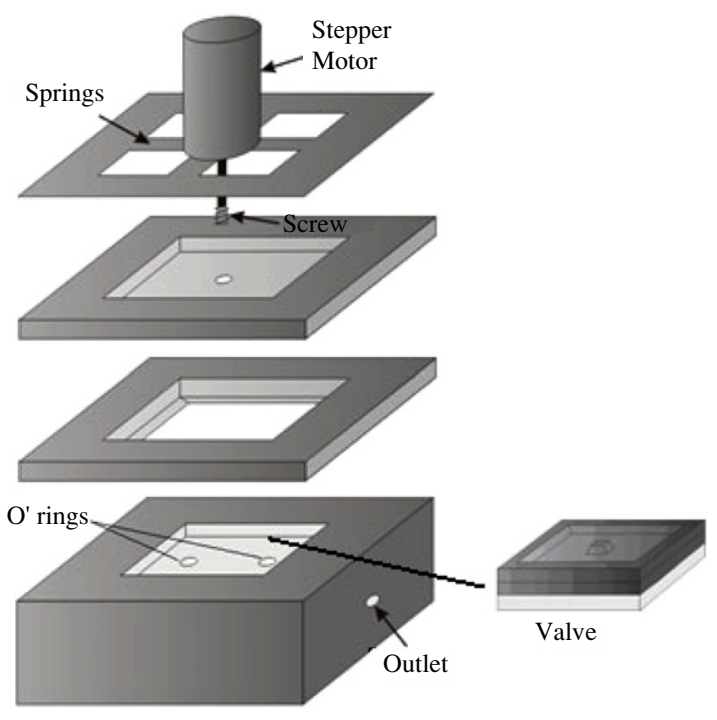

Figure 6. Aluminum metal block along with the micro stepper motor.

that in the case of variable resistance the Mach number is 0.9 at the maximum flow rate. This value is too high as it produces shock waves. For the case of static resistance in series with variable resistance, the Mach number reduces from 0.9 to 0.65 and it decreases linearly with the radial distance of the variable resistance. It can be concluded that this particular configuration with two resistances in series improves the performance of the valve by reducing the flow velocity as transonic speeds originate shock waves.

In order to check the theoretical model, we simulated the gas flow through the variable resistance. Compressible gas flow model is simulated as the theoretical model suggests compressible flow $(M a>0.3)$. It is found that the theoretical model does not show much deviation from the numerical model CFDRC (computational fluid dynamics).

\subsection{Fine-machined part}

The fine-machined part consists of an aluminum block and the micro stepper motor as shown in figure 6. The metal block includes inlet and outlet grooves. The microvalve is placed and tightened in such a way that inlet and outlet are aligned with the metal block. The micro stepper motor is mounted vertically on the top of the silicon membrane to deflect it (see figure 6).

The stepper motor is used as an actuator to deflect the membrane. The motor has to overcome the following forces:

- The force on the membrane as the flow impinges on it.

- The force due to the bending of the membrane.

- The frictional forces.

We need to know the forces to calculate the required torque to rotate the screw, the minimum displacement and the response time. To calculate the force caused by fluid on the membrane, it is assumed that there is static uniform pressure at the membrane above inlet $\left(a_{1}=0.2\right)$ as the valve is closed. It is approximated that the static pressure drops radially in the variable resistance as the valve opens. So with the boundary 
Table 2. Forces and torques required.

\begin{tabular}{|c|c|c|c|c|c|}
\hline \multicolumn{3}{|c|}{ Force } & \multicolumn{3}{|c|}{ Torque } \\
\hline \multicolumn{3}{|c|}{$F_{\text {pressure }}$} & \multicolumn{3}{|c|}{$T_{\text {bottom }}$} \\
\hline$a_{1}(\mathrm{~mm})$ & 0.2 & & $\mu_{\text {membrane }}$ & 0.4 & \\
\hline$a_{2}(\mathrm{~mm})$ & 2 & $1.88 \cong 2 \mathrm{~N}$ & $F_{\text {total }}(\mathrm{N})$ & 2.377 & $0.66 \mathrm{mN} \mathrm{m}$ \\
\hline Pressure (bars) & 4 & & $a_{\mathrm{s}}(\mathrm{mm})$ & 1 & \\
\hline \multicolumn{3}{|c|}{$F_{\text {total }}$} & \multicolumn{3}{|c|}{$T_{\text {thread }}$} \\
\hline$F_{\text {pressure }}(\mathrm{N})$ & 1.9 & $2.48 \cong 3 \mathrm{~N}$ & $F_{\text {normal }}(\mathrm{N})$ & 2.03 & \\
\hline$F_{\text {deflection }}(\mathrm{N})$ & 0.6 & & $\begin{array}{l}\mu_{\text {thread }} \\
a_{\mathrm{s}}(\mathrm{mm})\end{array}$ & $\begin{array}{l}0.6 \\
1\end{array}$ & $1.29 \mathrm{mN} \mathrm{m}$ \\
\hline
\end{tabular}

\begin{tabular}{llc}
\hline & \multicolumn{2}{c}{ Total frictional torque } \\
\hline$T_{\text {thread }}+T_{\text {bottom }}$ & & $1.95 \mathrm{mN} \mathrm{m}$ \\
\hline \multicolumn{3}{c}{ Total torque required by the motor } \\
\hline$T_{\text {friction }}(\mathrm{mN} \mathrm{m})$ & 1.95 & \\
$N$ & 120 & $T_{\text {motor }} 23.15 \mu \mathrm{N} \mathrm{m}$ \\
$\varepsilon$ & 0.7 & \\
\hline
\end{tabular}

conditions $p\left(a_{1}\right)=p_{1}$ and $p\left(a_{2}\right)=1 \mathrm{bar}$, the force on the membrane is given by

$$
\begin{aligned}
F_{\text {pressure }} & =a_{1}^{2} p_{1} \pi+\int_{a_{1}}^{a_{2}} 2 r p \pi(r) \mathrm{d} r \\
& =\pi a_{1}^{2} p_{1}+\frac{1}{3} p_{1} \pi\left(a_{1}+a_{1} a_{2}-a_{1}^{2}\right) .
\end{aligned}
$$

This gives the force on the membrane when the valve is almost closed. As the valve opens, the dynamic pressure increases, accordingly the static pressure reduces. The maximum force acting on the membrane is therefore due to the maximum static pressure which we take as 4 bar. This results in a force of $2 \mathrm{~N}$ on the membrane (see table 2).

The maximum force due to tensile stress in the membrane when the membrane is deflected can be approximated as [13]

$$
P=\frac{s_{\mathrm{d}} D}{0.0056 a_{\mathrm{m}}^{2}},
$$

where $a_{\mathrm{m}}$ is the side length, $s_{\mathrm{d}}$ is the membrane deflection and the flexural rigidity $D$ is given by

$$
D=\frac{h_{\mathrm{m}}^{3} E}{12\left(1-v^{2}\right)},
$$

where $h_{\mathrm{m}}$ is the thickness of the membrane, $E$ is the modulus of the elasticity and $v$ is Poisson's ratio.

The total force $(3 \mathrm{~N})$ is then the sum of the forces due to pressure (equation (5)) and the tensile force (equation (6)) as given in table 2 .

Frictional forces occur at two contact points: one where the end of the screw presses on the membrane boss, and the other in between the screw threads. To compute the frictional torque at the bottom, it is assumed that the force per unit area is uniformly distributed at the bottom of the screw. Then, the torque ( $T_{\text {bottom }}$ ) needed to overcome the friction between the membrane and the screw is calculated by the following expression and is given in table 2 :

$$
T_{\text {bottom }}=\frac{2}{3} \mu_{\text {membrane }} F_{\text {total }} a_{\mathrm{s}},
$$

where $\mu_{\text {membrane }}(=0.4)[14]$ is the coefficient of the friction between the membrane and the screw and $a_{\mathrm{s}}$ is the radius of the screw.
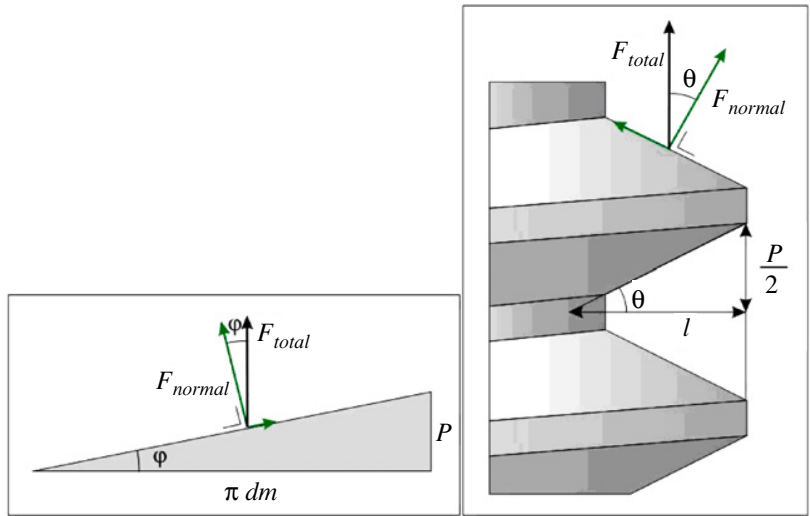

Figure 7. Screw threads.

Similarly, the torque needed to overcome the friction in screw threads is calculated. It can be seen in figure 7 that the frictional force in the thread is proportional to the force perpendicular to the upper plane of the thread and can be expressed as

$F_{\text {normal }}=\cos (\varphi) \cos (\theta) F_{\text {Total }}, \quad$ where $\quad \varphi=\arctan \left[\frac{p_{\mathrm{s}}}{d_{\mathrm{m}} \pi}\right]$,

where $d_{\mathrm{m}}$ and $P_{\mathrm{s}}$ are the mean diameter and pitch of the screw, respectively.

So the torque $(1.3 \mathrm{mN} \mathrm{m})$ needed to overcome the friction in threads is calculated as (see table 2)

$$
T_{\text {thread }}=\mu_{\text {thread }} F_{\text {normal }} a_{\mathrm{s}},
$$

where $\mu_{\text {thread }}(=0.6)$ [14] is the coefficient of the friction between the threads. The total frictional torque can be summed up and is $2 \mathrm{mN} \mathrm{m}$ (see table 2):

$$
T_{\text {friction }}=T_{\text {thread }}+T_{\text {bottom }} \text {. }
$$

The torque required by the stepper motor to overcome this total frictional torque is calculated by

$$
T_{\text {motor }}=\frac{T_{\text {friction }}}{N \varepsilon},
$$




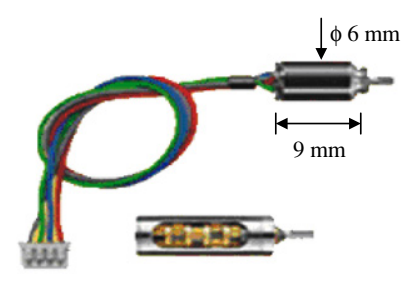

(a)

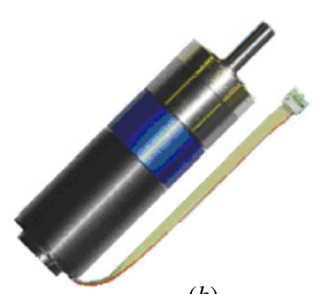

(b)
Figure 8. Micro stepper motor $(a)$ without a gearbox and $(b)$ with a gearbox.

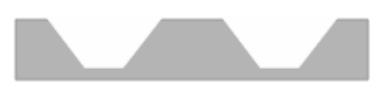

(a) KOH membrane in silicon

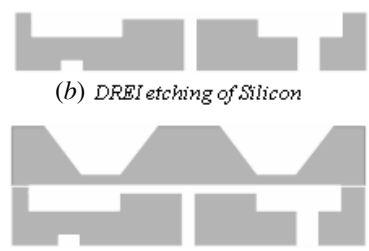

(c) Fusion bonding of Si-Si

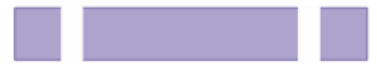

(d) Powder blasting of Pyrex

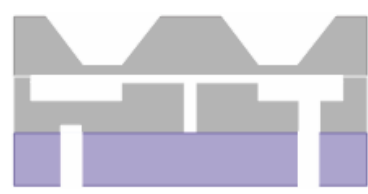

(e) Anodic bonding
Figure 9. Fabrication process for the micro-machined part.

Table 3. Displacement, steps and response time.

\begin{tabular}{lll}
\hline \multicolumn{3}{c}{ Minimum displacement $\left(\Delta_{\text {step }}=\frac{p_{s}}{N \cdot m}\right)$} \\
$p_{s}(\mathrm{~mm})$ & 0.4 \\
$m$ & $40 \quad 83 \mathrm{~nm}$ \\
$N$ & 120
\end{tabular}

$\begin{array}{ccc}\text { No. of steps } & \left(n=\frac{s_{\text {open }}}{\Delta_{\text {step }}}\right) \\ s_{\text {open }}(\mu \mathrm{m}) & 20 & 240 \\ \Delta_{\text {step }}(\mathrm{nm}) & 83 & \end{array}$

\begin{tabular}{lll}
\multicolumn{4}{r}{ Response time $\left(t_{\text {response }}=\frac{n}{v_{\mathrm{m}}}\right)$} \\
$n$ & 240 & $30 \mathrm{~ms}$ \\
$v_{\mathrm{m}}\left(\right.$ steps s $\left.^{-1}\right)$ & 8000 &
\end{tabular}

where $N$ is the gear reduction ratio and $\varepsilon$ is the efficiency of the gearbox.

Hence, the required motor torque as calculated from equations (11) and (12) is $23 \mu \mathrm{N} \mathrm{m}$. The smallest stepper motor ADM0620 (see figure 8) from the series of ADM0620, ADM0820 and ADM1020 can provide a torque of $200 \mu \mathrm{N} \mathrm{m}$ which is eight times more than the required torque. Moreover, it can provide better controllability as it can take smaller steps of $83 \mathrm{~nm}$ than $200 \mathrm{~nm}$ calculated initially (see table 3).

\section{Fabrication}

The fabrication process of the valve is straightforward as it includes standard micro-machining steps. It includes the micro-machining of three wafers as shown in figure 9. The fabrication is started with silicon membranes. They are fabricated primarily by deposition, patterning and $\mathrm{KOH}$ etching. A $150 \mathrm{~nm}$ thick high stress stoichiometric silicon nitride $\left(\mathrm{Si}_{3} \mathrm{~N}_{4}\right)$ layer is deposited on the silicon $\langle 100\rangle$ wafer, LPCVD process. This high stress silicon nitride layer is used as, when removed, it leaves the silicon surface smoother than when the silicon-rich nitride layer is removed. The silicon nitride is patterned from the topside of the wafer by RIE (reactive ion etching) defining the membrane and boss. $\mathrm{KOH}$ etching (with a time stop) is then used to etch the silicon wafer till the required membrane thickness of $50 \mu \mathrm{m}$ is reached. Finally, the nitride is removed by $50 \%$ HF to get the membrane with the boss as shown in figure $9(a)$.

To realize channels, variable resistance and orifices, a double-sided polished silicon $\langle 100\rangle$ substrate is used. As a first step, photoresist $(908 / 35)$, as a mask layer, is patterned on the backside of the substrate. Using the photoresist as a mask layer, $60 \mu \mathrm{m}$ rectangular channels are etched using the BOSCH process (B-Fast) for $15 \mathrm{~min}$ (see figure $2(d)$ ).

To fabricate the variable resistance and the orifice, three different layers are realized on the topside of the substrate. (1) A $1.2 \mu \mathrm{m}$ layer of $\mathrm{SiO}_{2}$ is grown by using wet oxidation of silicon at $1150{ }^{\circ} \mathrm{C}$. The $\mathrm{SiO}_{2}$ layer is patterned which defines the square chamber around the valve seat. With this step, the height between the valve seat and the membrane is defined. A $50 \mathrm{~nm}$ layer of chromium is deposited using a sputtering process (90 sccm Ar flow, $5.0 \times 10^{-3} \mathrm{mbar}, 200 \mathrm{~W}$ ). The chromium layer is patterned which defines the shape of the valve seat in the second etching step. Finally, a layer of photoresist (907-17) is patterned. This mask layer defines the orifice and outlet of the valve. Then, the three etching steps are followed to realize the variable resistance, chamber and orifice with the BOSCH process. The parameters used for the B-Fast process are temperature: $10{ }^{\circ} \mathrm{C}, \mathrm{C}_{4} \mathrm{~F}_{8}(2 \mathrm{~s}, 10 \mathrm{sccm}$, valve $100 \%$ ), SF6 (13 s, $400 \mathrm{sccm}$, valve $15 \%)$, ICP: $2500 \mathrm{~W}$, CCP: $10 \mathrm{~W}, \mathrm{SH}: 110 \mathrm{~mm}$, He: $0.7 \mathrm{sccm}$. Figures $9(b)$ and 2(b) show the middle wafer with channel, variable resistance, chamber and orifice. The inlet and the outlet are realized in the Pyrex wafer by a powder blasting process (particles $32 \mu \mathrm{m}$ $\left.\mathrm{AlO}_{2}\right)$ as shown in figure $9(d)$.

The two silicon wafers are fusion bonded at $1100{ }^{\circ} \mathrm{C}$ in $\mathrm{N}_{2}$. An Electronic Visions Aligner is used to align and to prebond the wafers. The final step is to anodically bond the fusion-bonded silicon wafers and the Pyrex wafer (see figure $9(e)$ ). The anodic bonding is performed on a hot plate setup.

We could not optimize the etching process for the different sizes of static resistances and valve openings which results in devices not having required static resistance $(w=800 \mu \mathrm{m}$, $h=60 \mu \mathrm{m}$ and $l=32 \mathrm{~mm}$ ) with a valve opening size of $60 \mu \mathrm{m}$.

\section{Experimental setup}

A schematic of the measurement setup is shown in figure 10 . A flow meter of Bronkhorst is used to measure the gas flow. The maximum volumetric flow for the flow meter that has been used is $220 \mathrm{ml} \mathrm{min}^{-1}$. The precision of the flow meter is $1 \%$ of the maximum flow. In front of the flow meter, an air filter is placed to purify air from dust particles, to avoid congestion of the valve. The pressure is measured by the pressure gauge in between the flow meter and the valve. 

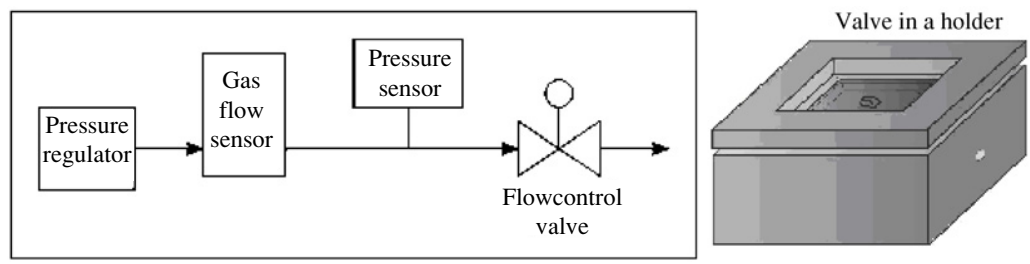

Figure 10. Schematic view of the experimental setup.

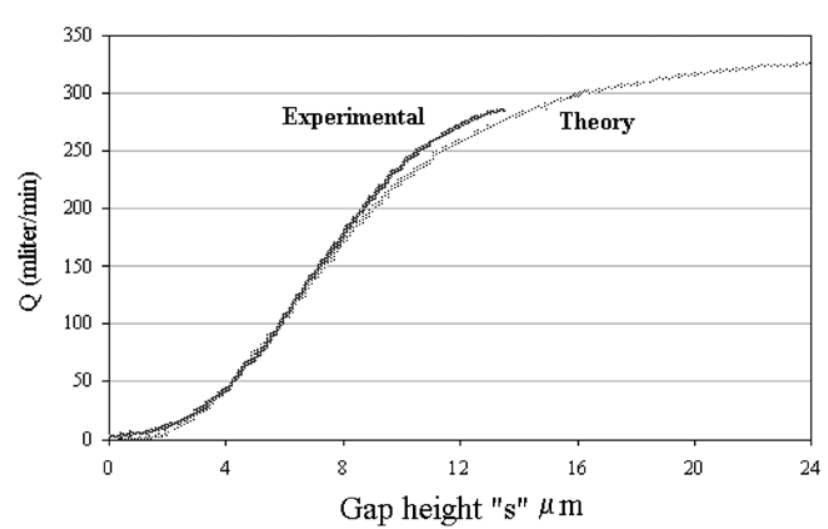

Figure 11. Comparison of experimental and theoretical flow rates.

\section{Results and discussions}

The flow rate is measured as a function of gap height. The measurement procedure starts with applying the pressure and closing the valve till a volumetric flow of $2 \mathrm{ml} \mathrm{min}^{-1}$. Then, the valve is gradually opened up to a gap height of $24 \mu \mathrm{m}$ and the flow rate is measured. The step size is set to approximately $1 \mu \mathrm{m}$. The volume flow rate is measured with four different pressure differences of 1,2, 3 and 4 bars between the inlet and outlet. Valves with five different lengths of the static resistance $(8,12,16,20$ and $24 \mathrm{~mm})$ were characterized. Figure 11 shows the measured volumetric flow rates at a pressure difference of 4 bar for a valve with a static resistance of $24 \mathrm{~mm}$ in length. It can be seen that the results predicted by the incompressible gas model are in good agreement with the measurements. Moreover, it can be observed that the volumetric flow rate exceeds a value of $200 \mathrm{ml} \mathrm{min} \mathrm{m}^{-1}$ at a gap height of approximately $9 \mu \mathrm{m}$. We attribute this increase in flow rates to the comparably low static fluidic resistance of the valve as we could not get the devices with higher static fluidic resistance (see section 3). The devices, used for experiments, were with low static resistance. That is why the flow reached the required value of $200 \mu \mathrm{m}$ at a smaller gap height of $9 \mu \mathrm{m}$ than of $20 \mu \mathrm{m}$.

The performance of the stepper motor has also been examined. To observe the hysteresis effect in gearbox, two different motors ADM0620 and ADM0820 with two different gear reduction ratios of 256:1 and 120:1 (zero backlash) were used respectively. Figure 12 shows the volumetric flow rate as a function of number of steps for a motor 'ADM0820' with a gear reduction ratio of 120:1. It can be observed from the plot that the volumetric flow rate of $220 \mathrm{ml} \mathrm{min}^{-1}$ is achieved within the 68 steps and with the equivalent gap height of $8 \mu \mathrm{m}$. This corresponds to a mean step size of $112 \mathrm{~nm}$, which differs from the calculated value of $83 \mathrm{~nm}$. This might be caused by the friction in the screw shown in figure 12 . It can be observed that a couple of small steps are followed by larger steps. During small steps, tension is built up due to the friction and when the force is high enough it takes the larger steps to overcome the friction. This phenomenon limits the controllability to $2-8 \mathrm{ml} \mathrm{min}^{-1}$ per step. In order to achieve required controllability, another stepper motor ADM0620 with a gear reduction ratio of 256:1 was used. In this case, the flow rate change of $0.5-4 \mathrm{ml} \mathrm{min}^{-1}$ per step was achieved. It is due to the smaller mean displacement of $51 \mathrm{~nm}$ per step with this motor. It is also seen that in the case of higher reduction ratio, we have a backlash problem, which results in hysteresis in

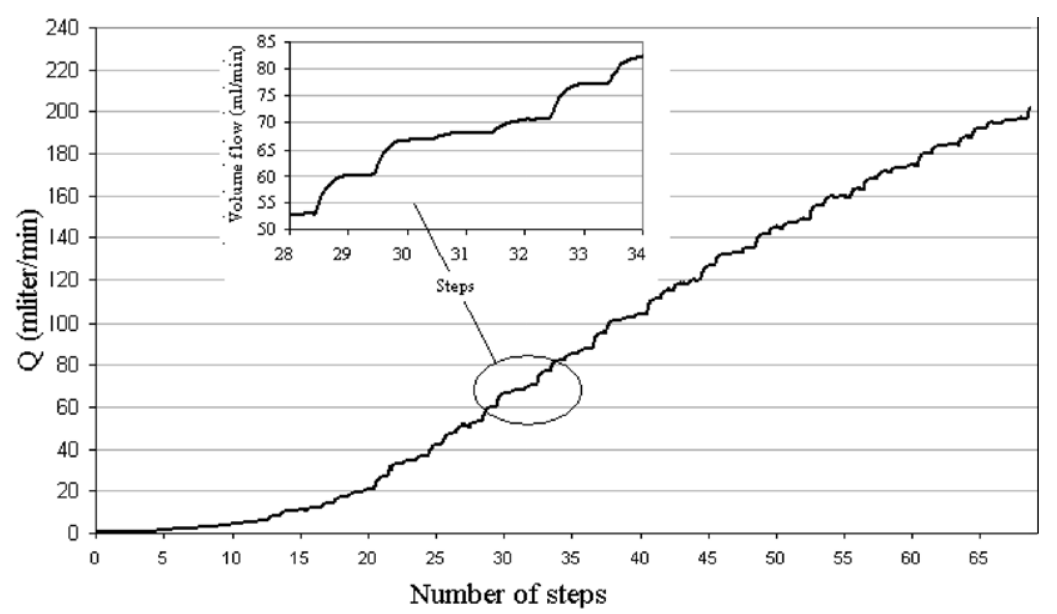

Figure 12. Stepper motor performance. 


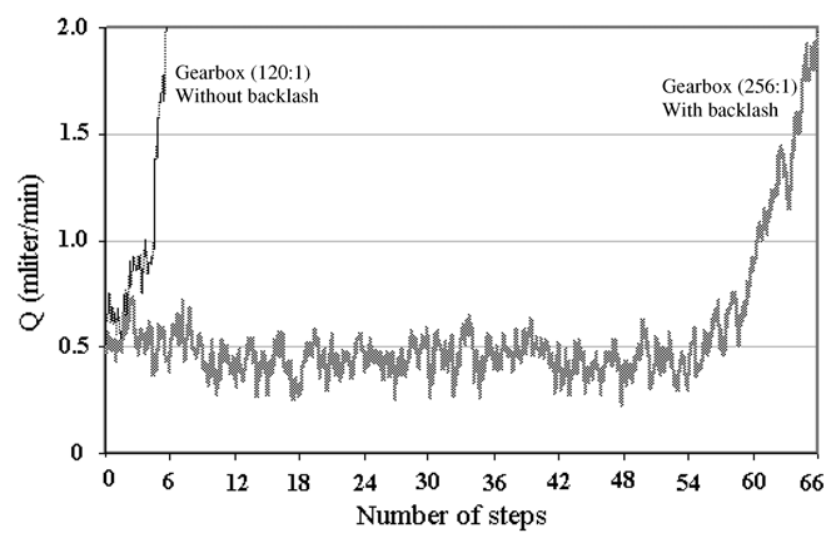

Figure 13. Comparison of stepper motor performance with different gearboxes.

the gearbox (see figure 13). This phenomenon causes delay in changing the direction of rotation of the stepper motor. We see from figure 13 that the gearbox with a reduction ratio of 256:1 needs approximately 60 steps to change direction whereas the gearbox without backlash with a reduction ratio of 120:1 takes 7 steps to change the direction.

Finally, leak testing of a microvalve was performed using a helium leak detector with atmospheric pressure at the inlet and vacuum $\left(1 \times 10^{-09}\right.$ bar $)$ at the outlet and extremely low leakage of $5 \times 10^{-6}\left(\mathrm{ml} \mathrm{min}^{-1}\right)$ was observed.

Summing up the results we did not find any deviation from the theory within the accuracy of our measurement. The good agreement of theory and experiment confirms our modeling assumption. Moreover, modeling shows that it is very difficult to include more pressure regimes in this particular design as the difference in resistance is large for the pressure difference higher than 5 bars. The valve performance can be affected by several factors including wear and tear in the screw mechanism and misalignment of the seat to the membrane. The frequent movement of the screw to deflect the membrane can cause wear which ultimately stops valve operation. Misalignment will increase the power necessary to seal the valve for a given flow. It is difficult to optically verify the alignment after assembly as the valve is in silicon.

This new design of the microvalve and its characterization presented above show promising improvement of such parameter as high flow rates, linearity, controllability at any stage with no power consumption as compared with valve currently available in the market.

\section{Conclusions}

A new technique has been presented to design and develop a microvalve, using a combination of fine- and micromachining. This technique enables us to control high flow rates at higher pressure. This new idea of mechanical transmission (conversion of rotational motion into the translation motion using stepper motor) not only allows us to control the valve at any intermediate state but also the valve does not need any power to keep its geometry. Additionally, this design prevents the interaction of the process gas with the actuation part, which enhances its robustness. A hard seating configuration, using fine- and micro-machining combinations, contributes to the enhanced leak tight microvalve operation. Extremely low leak rates of $5 \times 10^{-6}\left(\mathrm{ml} \mathrm{min}{ }^{-1}\right)$ were detected with atmospheric pressure at the inlet and vacuum $\left(1 \times 10^{-09}\right.$ bar $)$ at the outlet. Another promising feature is that it uses simple and straightforward fine- and micro-machining processes to realize the microvalve.

The promising results from the microvalve characterization presented in this paper provide the assurance that it is possible to meet the demanding requirements of high quality chemical analysis. The microvalve technology presented here is capable of integrating into fluidic devices and with other MEMS components. There are certain issues for future study. The robustness of the valve for practical applications against repeatability and aging needs to be tested. Finally, the geometrical design will be optimized to accommodate more pressure ranges in a single design.

\section{References}

[1] Shoji S and Esashi M 1994 Microflow devices and systems J. Micromech. Microeng. 4 157-71

[2] Yang E H, Lee C, Mueller J and George T 2004 Leak tight piezoelectric microvalve for high pressure gas micropropulsion J. Microelectromech. Syst. 13 799-807

[3] Huff A M and Schmidt A M 1992 Fabrication, packaging and testing of a wafer bonded microvalve IEEE Solid-State Sensor and Actuator Workshop, 5th Tech. Digest pp 194-7

[4] Messner S, Mueller M, Burger V, Schaible J, Sandmaier H and Zengerle R 1998 A normally closed bimetallically actuated 3-way microvalve for pneumatic applications MEMS 98: 11th Ann. Int. Workshop on Micro Electro Mechanical Systems pp 40-4

[5] Tomonari S, Yoshida H, Kamakura M, Yoshida K, Kawahito K, Saitho M, Kawada H, Juodkazis S and Misawi H 2003 Efficient microvalve driven by Si-Ni bimorph Japan. J. Appl. Phys. 42 4593-7

[6] Jerman H 1994 Electrically activated normally closed diaphragm valves J. Micromech. Microeng. 4 210-6

[7] Barth W P 1995 Silicon microvalves for gas flow control Transducer's 95 Eurosensors XI (Stockholm, Sweden)

[8] Rich C A and Wise K D 2003 A high flow thermopneumatic microvalve with improved efficiency and integrated state sensing J. Micromech. Syst. 12 201-8

[9] Bosch D, Heimhofer B, Muck G, Seidel H, Thumser U and Welser W 1993 A silicon microvalve with combined electromagnetic/electrostatic actuation Sensors Actuators A 37-38 684-92

[10] Yanagisawa K, Kuwano H and Tago A 1995 Electromagnetically driven microvalve Microsyst. Technol. 2 22-5

[11] Van der Pol F C M 1989 A Pump Based on Micro-Engineering Techniques 90-9003024-7 (University of Twente, FEBO, Enschede, The Netherlands)

[12] Khatait J P, Lin W and Lin W J 2005 Design and development of orifice-type aerostatic thrurst bearing SIMTech Technical Reports vol 6, no. 1

[13] Timoshenko S P and Woinowsky-Krieger S 1959 Theory of Plates and Shells (New York: McGraw-Hill)

[14] Bhushan B and Li X 1997 Micromechanical and tribological characterization of doped single-crystal silicon and polysilicon films for microelectromechanical systems devices J. Mater. Res. 1260 